\title{
Planejamento e gestão educacional no Brasil: hegemonia governamental e construção da autonomia local ${ }^{1}$
}

\section{Planning and educational management in Brazil: government hegemony and the construction of local autonomy}

\author{
Marília Fonseca* \\ Eliza Bartolozzi Ferreira** \\ Elisangela Alves da Silva Scaff ${ }^{* * *}$
}

\begin{abstract}
RESUMO
O texto analisa a política educacional brasileira a partir das últimas décadas do Século XX e início do Século XXI. Examina como a gestão e o planejamento educacional foram configurados nos diferentes governos que se sucederam ao longo do período de 1964 a 1985, que corresponde ao regime militar, orientado pela ideologia do crescimento econômico e da segurança nacional. Considera a fase democrática que o sucedeu como um período de mudanças em direção à inserção do País no processo de globalização econômica, quando se imprimiu um perfil gerencial à gestão e ao planejamento escolar, notadamente no contexto da Reforma do Estado de 1995. O texto analisa, ainda, o período 2003-2015, quando uma nova gestão governamental instituiu, em 2007, o Plano de Ações Articuladas (PAR). O objetivo principal do plano é estabelecer uma cultura de planejamento nas secretarias municipais de educação e nas escolas de ensino fundamental, como instrumento para consolidar a autonomia local.
\end{abstract}

1 Artigo elaborado a partir de Projeto de Pesquisa financiado pela Fundação de Apoio ao Desenvolvimento do Ensino, Ciência e Tecnologia do Estado de Mato Grosso do Sul (FUNDECT) e Conselho Nacional de Desenvolvimento Científico e Tecnológico (CNPq).

*Universidade de Brasília. Brasília, Distrito Federal, Brasil. E-mail: mariliasfonseca@gmail. com. https://orcid.org/0000-0002-3972-1556.

${ }_{* *}^{*}$ Universidade Federal do Espírito Santo. Vitória, Espírito Santo, Brasil. E-mail: eliza. bartolozzi@gmail.com. https://orcid.org/0000-0002-4100-9875.

*** Universidade Federal do Paraná. Curitiba, Paraná, Brasil. Email: elisscaff@gmail.com. https://orcid.org/0000-0002-7682-0879. 
Palavras-chave: Planejamento educacional. Gestão educacional. Autonomia local.

\begin{abstract}
The text analyzes the Brazilian educational policy from the last decades of the twentieth century and early 21 st century. It examines how the management and educational planning have been set up in the different governments that have taken place during this period. It begins concerning the political context of the military regime guided by the economic growth and national security ideology, considering then the democratic phase that succeeded it as a period of wide changes towards the country's integration into the economic globalization process, which has affected school planning and management, notably in the context of the 1995 State Reform. The text also highlights the period of 2003-2014, when a new type of school planning was instituted in 2007 by the Articulated Actions Plan (PAR). The main objective of the plan is to establish a culture of planning in the municipal education and elementary schools, as an instrument to consolidate local autonomy.
\end{abstract}

Keywords: Educational planning. Educational management. Local autonomy.

\title{
Introdução
}

O texto analisa o processo histórico de planejar a educação no Brasil nas últimas décadas do Século XX e início do Século XXI. Examina como a gestão e o planejamento educacional se configuram nesse período e em quais circunstâncias políticas o setor educacional se ajusta aos desígnios governamentais ou define suas ações com autonomia. Os dados aqui analisados provêm de uma pesquisa empírica dedicada ao tema da gestão e do planejamento educacional.

Como guia para a análise, leva-se em conta a ambivalência do planejamento, ao mesmo tempo como instrumento técnico e político. É técnico enquanto modo racional de definir ações prioritárias e os meios para o seu alcance. Sendo uma prerrogativa do Estado, traz em si a orientação política de cada gestão governamental. Não se pode perder de vista que o Estado, por via dos financiamentos, conta com expressivo poder de convencimento para impor seus propósitos à sociedade, afinal, como já alertou Weber (1994), o Estado tem o poder legítimo da força, exercendo a dominação sobre os homens e suas instituições.

Ainda assim, a execução de um plano de governo nem sempre se sustenta, em sua totalidade, em meio a ocorrências conjunturais imprevisíveis, oriundas da 
economia e do mercado de trabalho. O plano pode ser comprometido pela influência de grupos sociais que agem junto ao Estado como formadores de opinião por força de seu poderio econômico e político. Há que levar em conta, ainda, a mobilização de facções organizadas da sociedade, que aglutinam capacidade de reivindicação, mais ou menos contundente em diferentes fases governamentais.

Além das práticas legitimamente reconhecidas no âmbito do Estado pelos grupos de poder, há também as práticas patrimonialistas que perduram ao longo da história republicana - cujo início se deu no final do Século XIX (FAORO, 2014). Grosso modo, por força de seus pactos políticos com os quadros dirigentes, segmentos locais apoderam-se das regras de utilização dos meios administrativos e dos recursos financeiros e, por consequência, da distribuição de benefícios à população.

No Brasil, um plano de envergadura nacional é afetado também pela vontade política dos entes federados brasileiros (estados e municípios). Isso ocorre por força própria da organização federativa do país, instituída pela Constituição Federal de 1988, quando foi estabelecido o regime de colaboração entre os entes federados (União, estados e municípios).

Ainda que se leve em conta as diversidades econômicas e sociais que incidem no vasto território brasileiro, a materialização do planejamento estatal, como argumenta Ianni (1995), traz em si uma carga de controle e não deixa de expressar a ideologia hegemônica do Estado. Por essa razão, "o planejamento é um processo que começa e termina no âmbito das relações e estruturas de poder" (IANNI, 1995, p. 309). Dessa forma, o desenvolvimento da democracia passa a ser imprescindível para que o processo de planejamento seja assegurado em sua complexidade econômica e social. Isto significa a possibilidade de adicionar à tecnoburocracia estatal as discussões e expectativas da sociedade civil organizada, em resposta às suas demandas de emancipação política e econômica.

Os estudos de Ferreira (2013 e 2014) elucidam que a legitimação do conceito de planejamento fez parte de uma luta política ao longo da história republicana brasileira. Significa, acima de tudo, questionar sua condição de ser reconhecido como democrático e revelador dos interesses da maioria; de sua razão de existir e de ser legalizado e, no sentido estrito do termo, de ser cumprido. Resta, portanto, compreender as correlações de forças que compõem essa luta para conhecer a orientação dominante na concepção e na prática do planejamento. Para a referida autora as raízes da luta política pela autonomia do planejamento se estendem, ainda, para além da fronteira nacional (FERREIRA, 2013).

O planejamento esteve presente no Estado capitalista nacional como parte integrante de um projeto de desenvolvimento para um país, situado perifericamente na divisão internacional do trabalho. Esse processo não foi linear e nem mesmo sistemático, tendo em vista a correlação de forças presentes ao 
longo da história. Às vezes, o Estado nacional é concebido como uma solução para os problemas do capitalismo, outras vezes é encarado como um problema. Dependendo da forma mais ou menos tensionada com a qual o Estado lida com as injunções internacionais, afirma-se a sua soberania ou a atitude de submissão.

Compreendendo a prática de planejamento educacional a partir dos aspectos técnicos e políticos que perpassam a ação do Estado, e considerando os interesses econômicos e políticos, como também o modo pelo qual opera a organização federativa brasileira e a correlação de forças que se dá na sociedade civil, este texto é desenvolvido em três sessões. A primeira sessão apresenta uma síntese dos aspectos essenciais do planejamento estatal brasileiro; a segunda sessão contempla a trajetória do planejamento educacional a partir da Constituição Federal de 1988. A terceira sessão trata especificamente da pesquisa realizada sobre o PAR em parte dos sistemas municipais de educação do País.

\section{O planejamento estatal e a educação no Brasil: disputa entre valores conflitantes}

No período histórico analisado neste artigo - com início a partir da segunda metade do século XX -, o Estado brasileiro muniu-se de mecanismos capazes de fazer valer seu controle, pelo menos em boa parte dos séculos XX e XXI. Para isto, contou com o seu poder de convencimento, seja pelo viés autoritário ou pelo diálogo democrático. Por vezes, o projeto educacional seguiu uma diretriz utilitarista, ao limitar-se a dar suporte às demandas do projeto econômico do Estado. Nesse caso, o plano educacional deu ênfase à formação profissional, de modo a preparar trabalhadores para alavancar o crescimento.

Em fases mais democráticas, foi possível, especialmente pela mobilização dos trabalhadores docentes, discutir o plano à luz de propósitos valorativos, preparar o indivíduo para: gozar plenamente os seus direitos políticos; compreender e ter acesso às diferentes manifestações da cultura humana; atuar profissionalmente, munido de conteúdos éticos e da consciência de sua capacidade transformadora.

No início do percurso histórico aqui estudado, o processo de planejamento brasileiro acompanhou a tendência instituída na América Latina de utilizar planos de ação como meios para a superação das crises geradas no período pós Segunda Guerra Mundial. Os países dessa região sofreram com uma série de transtornos político-econômicos de âmbito global e, também, com a sobrecarga das demandas internas que ultrapassavam a capacidade de atendimento dos 
governos. Fazia-se urgente superar dificuldades, entre elas a inflação recorrente, o desequilíbrio da balança de pagamentos e a exportação centrada em produtos primários e agropecuários com pouco valor agregado.

Lavalle (2011) ressalta que essa crise foi acompanhada de forte movimento migratório no sentido campo-cidade, que gerou altas taxas de desemprego e uma demanda acirrada por serviços de habitação, água, saneamento, transporte e demais suprimentos de bens industrializados. Com o fato migratório, emergiram novos grupos sociais e, com eles, carências e demandas que ultrapassavam a capacidade instalada dos estados nacionais em atendê-las.

O Brasil sofreu esse fluxo migratório e, por conseguinte, as mesmas demandas sociais. Na década de 1940, foram realizadas algumas tentativas de planificação, porém, mais do que planejar propriamente, formularam-se instrumentos técnicos que se limitavam a organizar o processo orçamentário e a fixar metas para a consecução das prioridades da área econômica. Nessa década, foram várias as tentativas de coordenar, controlar e planejar a economia brasileira. Como informa Lafer (2001), essas tentativas não puderam ser enquadradas como planejamento propriamente dito, visto que se restringiram a apresentar propostas para reorganizar o processo orçamentário, tais como: o Plano Salte (1948), o Relatório Simonsen (1944-1945) ou propostas inspiradas em diagnósticos norte-americanos, no caso da Missão Cooke (1942-1943), da Missão Abbink (1948) e da Comissão Mista Brasil-EUA (1951-1953).

O planejamento só teria ganhado consistência na América Latina, no limiar da década de 1960, quando entidades internacionais de assistência técnica e financeira, em conjunto com algumas entidades regionais das Nações Unidas para a América Latina, incentivaram a elaboração de planos estatais com o objetivo de impulsionar o desenvolvimento da região, inclusive como pré-requisito para que os governos tivessem acesso aos créditos de organismos financeiros internacionais. Os diferentes estilos políticos adotados em cada fase governamental deram o tom das relações entre o Estado e as corporações internacionais e, internamente, entre as relações da União com os demais entes federados.

O planejamento fortaleceu-se nessa época com a participação de entidades internacionais de caráter econômico e financeiro - o Fundo Monetário Internacional (FMI) e o Grupo Banco Mundial -, cujo objetivo voltava-se para a elaboração de planos a fim de reorganizar a economia dos países europeus afetados pela Segunda Guerra Mundial. Nos anos 1960, a ação dessas organizações estendeu-se para a América latina na forma de cooperação para o desenvolvimento. A cooperação se concretizava, notadamente, por meio de empréstimos financeiros destinados à execução de projetos de base para o crescimento econômico dos países, com a intermediação da Comissão Econômica para a América Latina (CEPAL). 
Sob os auspícios da Organização dos Estados Americanos (OEA), foram organizadas conferências internacionais para o desenvolvimento. O destaque coube às conferências organizadas no Uruguai e em Santiago do Chile (1961 e 1962). Os países partícipes firmaram o compromisso de levar adiante as orientações da Cepal e, também, de aderir a um novo programa de cooperação econômica criado pelo governo Kennedy nos EUA denominado Aliança para o Progresso.

Segundo as recomendações das conferências, o planejamento estatal ganhou força, inclusive como pré-requisito para que os governos tivessem acesso aos créditos de organismos financeiros internacionais. Além da OEA, os citados eventos contaram com o patrocínio da Agência Internacional para o Desenvolvimento (Usaid), vinculada ao Departamento de Estado Norte-Americano. Por meio de acordos bilaterais com o governo brasileiro, a Usaid deu suporte técnico e financeiro ao processo de crescimento econômico e à reestruturação da gestão pública - inclusive no setor educacional - que incluíam o aporte de metodologias gerenciais já utilizadas na administração estatal norte-americana.

Os planos educacionais brasileiros adequaram-se, em parte, aos objetivos estabelecidos pelas conferências internacionais, notadamente quanto à incorporação da educação aos planos de desenvolvimento dos governos e também à fixação de metas educacionais homogêneas para toda a região latino-americana. A proposta internacional difundia o método de planejamento conhecido como Enfoque de Mão-de-obra (Manpower approach), que fixava as metas de um plano de educação de acordo com o quantitativo e as competências exigidas pelo mercado de trabalho. O método era complementar à Teoria do Capital Humano, segundo a qual o desenvolvimento dos recursos humanos pelo sistema educacional é entendido como requisito essencial para o crescimento econômico dos países. A educação, em todos os níveis, deveria, portanto, produzir competências para o emprego e agregar valor aos recursos humanos no mercado (FONSECA, 2013).

A primeira experiência para gerar um planejamento governamental abrangente no Brasil, com a incorporação do setor social - a educação inclusive -, ocorreu na construção do Plano de Metas, durante o governo do Presidente Kubitschek de Oliveira (1956-1960). A educação foi incorporada ao seu programa de governo com o propósito de preparar pessoal técnico para a implantação das indústrias de base, carro-chefe do projeto de desenvolvimento. Apesar do vigor das recomendações internacionais, o período de 1956 a 1963, que abrangeu os governos democráticos de Kubitschek e de Goulart, foi profícuo para a mobilização dos trabalhadores docentes, que voltaram a debater as suas ideias em fóruns nacionais.

Congregados no Instituto Superior de Estudos Brasileiros, trabalhadores docentes e outros intelectuais dirigiam suas críticas à recomendação internacional 
de subjugar o planejamento da educação às metas do crescimento econômico e, ainda, de se definir metas homogêneas para a América Latina, sem considerar a realidade de cada país. A mobilização civil levou o governo a imprimir uma feição nacional às metas educacionais, coadunando-as à realidade brasileira. $\mathrm{O}$ Plano educacional do governo seguinte, de João Goulart (1961-1963), incorporou a visão dos educadores, porém não teve continuidade devido à destituição do presidente e da instauração do regime militar, que perdurou de 1964 a 1985.

Nos vinte anos dos governos militares, imprimiu-se nova conformação à gestão e ao planejamento governamental. A educação passou a integrar os planos econômicos, com o propósito de preparar mão-de-obra para o crescimento, cujo objetivo central era criar um parque industrial moderno como base para a consolidação do "Brasil Potência". O Banco Mundial e a Agência para o Desenvolvimento Internacional (Usaid) tornaram-se os parceiros mais íntimos no processo de definição da agenda educacional brasileira. Os acordos de cooperação técnica e financeira firmados entre essas agências e o Ministério da Educação foram efetivos para configurar a reforma da educação superior de 1968 e também da educação básica, pela Lei nº 5.692 de 1971 . O viés economicista da lei provocou profundas mudanças, entre elas a reestruturação curricular, atribuindo prioridade às disciplinas do campo profissionalizante, de acordo com a doutrina do Capital Humano.

No final da década de 1970, ocorreu a desaceleração do ritmo de crescimento e aguda aceleração inflacionária no País. Além das razões internas, a crise energética mundial também enfraqueceu a capacidade produtiva do Estado brasileiro, além de atrofiar, de forma progressiva, os mecanismos estatais de decisão e sustentação de políticas de longo prazo. Segundo Fiori (1995), a crise financeira quase obrigou o governo a declarar a moratória da dívida externa e o impeliu a tomar uma posição ambígua, entre uma opção desenvolvimentista e uma gestão estabilizadora.

Em decorrência desses fatos, o início da década de 1980 caracterizou-se como um período de crise econômica, acelerada pelo aumento da inflação e de dificuldades para o pagamento da dívida externa brasileira. $\mathrm{O}$ regime militar entrou em crise e procedeu uma transição democrática negociada. Os setores empresariais e políticos, que se beneficiaram do Estado desenvolvimentista, passaram a atacá-lo, sob o argumento das teses neoliberais que voltavam a defender a primazia do mercado no contexto da globalização.

Dessa forma, a política de crescimento econômico, embalada pelos planos de desenvolvimento da gestão militar, foi substituída no final da década de 1980 por uma política de ajustes para garantir a estabilidade econômico-financeira e o combate à inflação como exigências para que o país participasse dos processos de globalização. Já em meados da década de 1980, os ajustes eram monitorados 
pelo Fundo Monetário Internacional (FMI). Fiori (1995) informa que o planejamento estatal restringiu-se a 8 planos de estabilização monetária no Brasil, 4 diferentes moedas, 11 índices de cálculo inflacionário, 5 congelamentos de preços e salários, 14 políticas salariais, 18 modificações nas regras de câmbio, 54 alterações nas regras de controle de preços, 21 propostas de negociações da dívida externa e 19 decretos governamentais a propósito da austeridade fiscal.

Em meio à desorganização estatal, intensificou-se a pressão das classes populares e das organizações sociais, notadamente os sindicatos, por um reconhecimento integral de seus direitos políticos, sociais e econômicos. Segundo o estudo de Fonseca e Ferreira (2011), as dificuldades econômicas mundiais que marcaram a década de 1980 contribuíram para o enfraquecimento financeiro dos estados brasileiros. No final da década, as teses neoliberais ganharam força e facilitaram a conciliação dos interesses dos setores dominantes, ao mesmo tempo em que bloquearam o avanço das classes populares na conquista dos seus direitos. Tornou-se, pois, imprescindível aliviar o mercado dos constrangimentos econômicos e deixá-lo livre. Essa foi a justificativa para a instalação das políticas neoliberais na década de 1990.

No campo das políticas educacionais, esse movimento pode ser caracterizado a partir de um deslocamento da esfera da democratização (luta dos trabalhadores docentes no período da constituinte) para o universo da modernização, pois, para a política nacional e internacional, o mais urgente passa a ser os objetivos da racionalização e da otimização, desafios consagrados no contexto atual, dominados pela ideologia do tipo neotayloriano (DUARTE; FERREIRA, 2012).

\section{Planejamento e educação: o padrão gerencial moldando a gestão escolar}

Na década de 1980, o planejamento educacional passou a sofrer influência mais decisiva do Banco Mundial. De acordo com o estudo de Fonseca (2009), por meio de uma série de acordos com o Ministério da Educação (MEC) para o financiamento da educação básica, as diretrizes políticas fixadas pelo Banco passaram a compor os planos educacionais (BRASIL/MEC, 1980; 1986). É legítimo supor que os países, ao acatarem a orientação de agências internacionais para a construção dos planos e projetos, internalizam também os valores, objetivos e métodos implícitos aos modelos internacionais de planificação. Concorrem para isto as condições políticas e metodológicas impostas nas cláusulas dos empréstimos concedidos por agências financiadoras, notadamente o Banco Mundial. 
A Unesco² (órgão da ONU para a educação), por sua vez, não atua como agência de financiamento (não obstante ser um captador financeiro), mas detém o poder de influenciar políticas educacionais, notadamente no nível superior de ensino, ao reunir os países em torno de eventos mundiais de larga escala.

A intensidade da influência internacional tem a ver com a forma - compartilhada ou autonômica - com que os governos interagem com o campo internacional. Em meio à crise dos anos 1980, os projetos financiados pelo Banco Mundial para a educação básica traziam ao Ministério da Educação propostas concebidas a priori pelo seu staff. Entre esses projetos, destacam-se os modelos de planejamento de cunho gerencial para as escolas de educação básica, com o objetivo de adequar os "processos gerenciais e organizacionais para dar lugar à utilização dos insumos e produtos e à avaliação dos seus resultados" (BRASIL/ MEC, 1986, p. 21). A intenção era diversificar as fontes de financiamento para a educação básica e redimensionar os gastos com base em avaliações de larga escala e com a capacitação técnico-pedagógica e gerencial de profissionais da educação.

O esforço para garantir a governabilidade e a inserção do país na ordem global fortaleceu-se na gestão de Fernando Henrique Cardoso (1995-2002). Os oito anos de seu governo foram marcados por um processo de estabilidade política, o que garantiu a continuidade do planejamento. Além disso, o governo primou em consolidar a reforma do Estado, mediante um processo de qualificação de técnicos (organizados pela Escola Nacional de Administração Pública) que estivessem diretamente envolvidos com a elaboração e execução dos planejamentos plurianuais (BRASIL/MARE, 1995).

Ferreira (2007) lembra que os investimentos em infraestrutura na área social, no meio ambiente ou no campo moderno da informação e do conhecimento iriam reduzir o chamado Custo Brasil, como queria o governo. A Reforma do Estado de 1995 estabelecia para a administração pública federal a gestão por resultados, a integração entre plano, orçamento, gestão e gerenciamento e avaliação de desempenho em todos os programas do governo federal. Para a conclusão do processo, foi acelerado o Programa Nacional de Desestatização, responsável pela privatização e concessão de serviços públicos à iniciativa privada. $\mathrm{O}$ novo modelo beneficiaria o Brasil pelo fato de que os custos dos serviços passariam a assemelhar-se aos do mercado internacional e pela introdução da concorrência e do fortalecimento gerencial e financeiro das empresas.

O enfoque gerencial internalizado no âmbito das reformas do Estado tornou a gestão pública mais técnica, oferecendo soluções racionais, supostamente

2 United National Educational, Scientific and Cultural Organization. Tradução: Organização das Nações Unidas para a Educação, Ciência e Cultura. 
neutras, para o enfrentamento dos problemas econômicos e sociais. O processo preconizado não se deu de forma linear, já que se atrelava a uma prática social configurada historicamente e que se mantinha sob a vigilância de setores organizados da sociedade.

Segundo o documento que analisa o processo de planejamento estatal nesse período (BRASIL/MPOG, 2002), buscava-se adequar o país ao movimento de modernização da gestão pública que estava em curso no mundo, iniciado nos anos 1980. Tais transformações, definidas na reforma do Estado brasileiro (BRASIL/ MARE, 1995), afetaram significativamente o campo da educação, sobretudo a educação escolar, modificando finalidades, valores e práticas educativas.

Um dos objetivos mais reiterados nas reformas da educação básica centrou-se na descentralização administrativa, compreendida como meio de transferir para a escola a responsabilidade pela eficiência administrativa, a eficácia do ensino e também parte do seu financiamento. Para isto, a gestão passou a ser o instrumento para se afirmar uma nova cultura escolar, inspirada em modelos organizacionais que incorporassem estratégias de autonomia e liderança no âmbito das instituições descentralizadas. De acordo com as orientações da reforma do Estado de 1995, as instituições públicas deveriam adotar modelos gerenciais próprios do setor privado, inclusive no que se refere ao planejamento e à organização do trabalho escolar.

A racionalidade imposta à gestão pública brasileira ajustava-se ao cenário neoliberal dos anos 1990, descrito por Lojkine (1995) e Rifkin (1995), que tinha a ciência e a inovação tecnológica como forças produtivas fundamentais, uma vez que o conhecimento, o saber e a ciência assumiam papel destacado em todos os setores (indústria, agricultura, serviços, lazer). A agenda educacional, assim como as instituições educativas, modificaram seus objetivos e suas prioridades. Redefiniram-se as finalidades das instituições públicas, da educação básica à educação superior, visando à demarcação de perfis profissionais ajustados à formação requerida pelo mercado.

Newman e Clarke (2012) consideram tal atitude como a transferência de um ethos de negócios do setor privado para o Estado e o setor público, mesmo onde os serviços públicos não são totalmente privatizados, uma vez que se exige um desempenho marcado pela competitividade. Essa tendência se evidencia no Brasil por meio de transferência de recursos e de atribuições para os níveis políticos regionais e locais; pela delegação de autoridade aos administradores públicos que se transformam em gerentes progressivamente autônomos; pelos objetivos a serem atingidos na forma de indicadores de desempenho, sempre que possível, quantitativos, como requisito do contrato de gestão entre o poder central e os dirigentes locais (SCAFF, 2011). 
O Plano Nacional de Educação elaborado no final da década de 1990 (PNE/2001), em um processo dicotômico entre segmentos da sociedade civil e do governo federal perdeu força no âmbito do MEC. Priorizou-se a proposta estratégica do governo, cuja intenção declarada era dividir os custos da educação com a sociedade, desconsiderando a escola como um direito, mas como dever da família, da sociedade e da comunidade. A gestão educacional - e especificamente a gestão escolar - passou a orientar-se pelo modo gerencial, que foi, sem dúvida, uma estratégia para levar as instituições escolares a trilhar modelos técnicos de planejamento que tomam o mercado como exemplo de eficiência.

De acordo com resultados da pesquisa realizada por Fonseca, Toschi e Oliveira (2004), o projeto que difundiu os preceitos gerenciais originou-se de um acordo técnico-financeiro firmado em 1998 entre o MEC e o Banco Mundial para o desenvolvimento do Programa Fundo de Fortalecimento da Escola (Fundescola). Além da orientação do banco para gerir o projeto, o MEC buscou o apoio do Programa das Nações Unidas para o Desenvolvimento (Pnud), especialmente para a contratação de consultores nas áreas de planejamento estratégico.

O citado estudo (FONSECA; TOSCHI; OLIVEIRA, 2004) identificou que o planejamento desenvolvido pelo Fundescola ajustava-se ao Plano Plurianual de governo de Fernando Henrique Cardoso para o período 1996-1999: Avança Brasil. A organização das ações escolares dar-se-ia na forma de projetos, cada um deles sob a responsabilidade de um professor gerente. O alvo principal da gestão era a eficiência, compreendida com a contenção dos gastos da escola e a definição de objetivos orientados racionalmente para resultados ou produtos. A escola adaptava-se, assim, a uma organização sistêmico-funcionalista, voltada para prover soluções aos problemas que emperram o "funcionamento do sistema", como exemplo, a evasão, a repetência, a distorção idade-série e o baixo rendimento escolar. Segundo a especificação de Torre (1997), esta forma organizativa implica executar as fases técnicas do planejamento: definir os insumos de entrada (objetivos iniciais) e organizar as ações segundo as fases de difusão, adaptação, implementação e, finalmente, a avaliação de resultados.

Outra opção apresentada na proposta gerencial era o aproveitamento do know-how e da capacidade instalada do setor privado, estabelecendo parcerias com empresas e organizações não governamentais para melhorar a qualidade do ensino público. Propunha-se a formação de redes entre escolas públicas e privadas, nas quais as últimas pudessem oferecer assistência técnica, material e de treinamento de professores às escolas públicas, especialmente às que atendessem estudantes de baixa renda. Esse desenho coadunava-se com a definição do enfoque gerencial de Newman e Clarke (2012, p. 359), que o identificam como "uma ideologia que legitima direitos ao poder, especialmente ao direito de gerir, construídos como necessários para alcançar maior eficiência 
na busca de objetivos organizacionais e sociais”. A gestão pública, em sua acepção gerencial, foi justificada como indispensável ao desenvolvimento do país em face do movimento mundial em torno do crescimento econômico por via do aumento da produtividade.

A proposta gerencial realizava-se por meio de um fundo governamental repassado às escolas, por meio do Plano de Desenvolvimento da Escola (PDE). O objetivo era estimular o quadro administrativo a tomar decisões que afetassem materialmente a escola e a responsabilizar-se pelos resultados de suas decisões. Após a divisão das atividades em metas, completava-se a estrutura gerencial com a definição dos líderes de objetivos, dos gerentes de metas e das equipes executoras dos planos de ação. Os principais responsáveis pelos resultados (ou eficiência) das ações eram os tomadores de decisão na escola. De acordo com a meta de reduzir o Custo Brasil, cabia-lhes buscar outras formas de financiamento para as atividades escolares por meio de campanhas e eventos para estimular a contribuição voluntária da comunidade. Recaía, pois, sobre a direção da escola uma sobrecarga de trabalho, obrigando-a a gastar grande parte do seu tempo em atividades de pouca monta que não visavam diretamente o núcleo pedagógico da escola.

Na primeira gestão do Presidente Luiz Inácio Lula da Silva (2003-2010) foi efetuado um esforço para equilibrar as tensões que se produziam no embate de forças entre as demandas internacionais do campo econômico-produtivo e aquelas que provinham da mobilização dos educadores em prol de um projeto autônomo para a educação. A estreita parceria estabelecida na década de 1990 entre o governo brasileiro e as entidades internacionais na área da educação sendo a mais representativa o Banco Mundial - sofreu um arrefecimento no governo Lula da Silva. A partir daí, não foram assinados outros acordos para o financiamento da educação.

O Plano Plurianual de Governo (2004-2007) seguiu um viés mais social com o intuito de corrigir a histórica desigualdade entre regiões, pessoas, gêneros e raças. A prioridade para as políticas sociais evidencia-se no próprio titulo do plano "Orientação estratégica de governo um Brasil para todos: crescimento sustentável, emprego e inclusão social” (BRASIL, 2003, p. 15). Os frequentes contingenciamentos da verba pública, combinados com a ausência de articulação entre os órgãos governamentais, fizeram com que o plano fosse mais direcionado à tentativa de manter a estabilidade econômica e o equilíbrio fiscal.

Como estratégia política, o governo concentrou-se no fortalecimento do diálogo com os entes federados (União, estados e municípios), valendo-se do disposto na Constituição aprovada em 1988, quando os municípios foram elevados a entes federados e, portanto, dotados de autonomia.

Essa questão mereceu uma tese elaborada por Martins (2009), que analisou a base do planejamento educacional a partir da estrutura do sistema federativo 
brasileiro. Como a Federação consiste na união de coletividades regionais autônomas, denominados entes subnacionais, supõe-se o compartilhamento do poder, sem o qual a autonomia dos entes não se realiza de forma plena. Ainda que as regras de redistribuição de recursos para os entes subnacionais expressem a vontade soberana de um país, ao mesmo tempo, a autonomia implica o equilíbrio federativo no qual a relação entre os entes se faz sob a égide do regime de colaboração. Assim, a Federação se constitui pelo compartilhamento de poder de coletividades regionais e locais autônomas, sem o qual a autonomia não se realiza. Por se tratar de um pacto selado pela Constituição Federal Brasileira de 1988, qualquer elemento que atue negativamente sobre essas dimensões perturba o equilíbrio federativo. A partir desse entendimento, o segundo governo de Lula da Silva (2007-2010) induziu uma política de planejamento educacional aos entes subnacionais, com apoio técnico e financeiro, para a melhoria da oferta da educação básica.

\section{O Plano de Ações Articuladas como opção alternativa ao padrão gerencial de administrar a escola}

A prioridade para a educação efetivou-se no segundo mandato de Lula da Silva (2007-2010), como mostra o título do seu plano de governo "Desenvolvimento com Inclusão Social e Educação de Qualidade” (BRASIL, 2007a). Tal objetivo foi materializado por meio de instrumentos para fortalecer o financiamento aos estados e municípios, como a ampliação da política do fundo de financiamento da educação para toda a educação básica, por meio da criação do FUNDEB, bem como a criação do Plano de Desenvolvimento da Educação (PDE) e de seu programa estratégico: o Plano de Ações Articuladas (PAR), instituído pelo Decreto ${ }^{\circ} 6.094$ (BRASIL, 2007b).

O PAR se apresentou como um instrumento para garantir a colaboração entre os entes federados, conectando um conjunto de programas desenvolvidos pelos três subsistemas de governo - União, estados e municípios. A colaboração dar-se-ia de acordo com o $\S 5^{\circ}$ do referido decreto ao estabelecer a responsabilidade da União de estimular os municípios para que se responsabilizem pela elaboração dos seus planos de educação, apoiados técnica e financeiramente pelo Ministério da Educação.

Para tanto, o Governo Federal disponibilizou instrumentos a fim de orientar o planejamento nos municípios a partir de quatro dimensões, quais sejam: gestão 
educacional; formação de professores e de profissionais de serviços e apoio escolar; práticas pedagógicas e avaliação; infraestrutura física e recursos pedagógicos.

A proposta era que o PAR fosse construído de forma participativa, com o intuito de promover a presença ativa dos gestores e educadores locais, das famílias e da comunidade. Portanto, o PAR estimulava uma ação autônoma dos sistemas educacionais a partir de uma tecnologia que poderia garantir apoio do MEC ao mesmo tempo em que apresentava um campo de possibilidades para os entes federativos na ação de planejar sua oferta escolar.

No que se refere ao enfoque de planejamento, o PAR se propôs a desenvolver programas articulados, integrando o trabalho escolar em um conjunto orgânico, a partir de quatro eixos norteadores, quais sejam: educação básica, educação superior, educação profissional e alfabetização. Dessa forma busca-se estruturar uma "perspectiva sistêmica da educação", isto é, promover a articulação entre o ensino fundamental e o ensino superior, o incentivo à pesquisa $\mathrm{e}$ o ensino médio, entre outros.

Assim formatado, o plano pressupõe superar a fragmentação das ações educacionais, próprias do modelo de planejamento por objetivos, como ocorria no mencionado Programa de cooperação financeira entre o Banco Mundial e o MEC (Fundescola). Para alcançar uma organização sistêmica, no sentido que lhe dá o PAR, há que se liberar da tutela de técnicas pontuais para garantir determinados produtos ou para solucionar problemas pontuais. As ações deveriam ser pensadas em sua amplitude política, isto é, como parte de um projeto pedagógico que compreenda e organize a educação como um todo.

O Plano de Ações Articuladas mereceu a adesão da totalidade dos mais de cinco mil municípios brasileiros. A proposta de planejamento foi acolhida como uma forma inovadora de planejar as ações dos sistemas educacionais. $\mathrm{Na}$ sua segunda fase de execução, o plano foi objeto de argumentações que puseram em questão a sua efetividade para as transformações necessárias no campo da educação em nível local. De acordo com os resultados da pesquisa que dá suporte a esta análise, ainda que no plano constitucional os municípios sejam autônomos, no plano econômico, social e administrativo são marcados por dificuldades orçamentárias, estruturais, administrativas e pedagógicas que os faz ainda dependentes de uma política de Estado capaz de ajudar a superá-las.

Entre as questões evidenciadas pelos dados da pesquisa, percebe-se, primeiro, que algumas consequências das políticas do governo anterior ainda se faziam perceber na gestão da educação básica. O modo gerencial de planejar e executar as ações estava presente em parte dos municípios pesquisados, que muitas vezes associavam o PAR a um instrumento burocrático a ser preenchido para a obtencão de recursos financeiros junto ao governo federal. 
Outras práticas foram observadas a partir da continuidade de ações que favoreciam diretamente o setor privado, tais como as parcerias com entidades não governamentais ou privadas que continuavam se expandindo em numerosos municípios por meio de diferentes estratégias, por exemplo, sob a forma de Arranjos de Desenvolvimento da Educação (ADEs), regulamentados pela Resolução n. 1/2012 do Conselho Nacional de Educação (CNE). Desse modo, muitas organizações não governamentais e até mesmo empresas, por meio dos $\mathrm{ADEs}$, interferiram na educação municipal, geralmente fazendo uso de recursos do PAR, pois havia um rol de programas e projetos vinculados a essas empresas nos guias de tecnologias dos sistemas educativos, como analisado por Scaff e Fonseca (2016).

Na pesquisa realizada junto aos sistemas municipais de educação, observamos que, além de se caracterizar como uma forma de intervenção na educação pública, as parcerias apresentavam resultados educacionais nada eficientes. O que se pode constatar foi o estabelecimento de uma relação de subordinação dos profissionais da educação aos objetivos das organizações do setor privado, de forma a comprometer a autonomia administrativa e pedagógica dos sistemas municipais de ensino.

Outra questão que alimenta o debate acadêmico diz respeito ao compromisso do PAR com a qualidade do ensino, visto que considera o Índice de Desenvolvimento da Educação (IDEB) como o indicador para a verificação da qualidade. A proposta do MEC é que este índice alcance a média de 6,0, equivalente à média dos países desenvolvidos que integram a Organização para a Cooperação e Desenvolvimento Econômico (OCDE). Não obstante, os limites do Ideb na avaliação da qualidade do ensino brasileiro, os dados evidenciam seu crescimento, o que equivale a dizer que, neste aspecto em particular, o ente federado, sobretudo o município, teve sucesso com a implantação do PAR.

Os dados empíricos, no entanto, não asseguram vislumbrar essa equação de forma simples. De maneira geral, a pesquisa evidenciou o esforço de muitos sistemas educativos com a tarefa de planejar a educação, mas também observamos sérias dificuldades nessa ação, sobretudo, pela ausência de profissionais concursados nas secretarias de educação e, também, pelo fato dos profissionais administrarem outros diversos programas que chegavam como demandas dos governos nacional e locais que, muitas vezes, eram dissonantes com uma perspectiva inclusiva para uma educação emancipadora. Ademais, a cultura do planejamento educacional nos sistemas educativos depende da manutenção de uma política (o PAR é um exemplo) em um tempo mais longo e legalmente instituído na gestão educacional como forma de construir e fortalecer a autonomia dos sistemas educacionais do País. 


\section{Considerações finais}

O estudo aqui apresentado evidencia a intensa influência das agências internacionais no planejamento educacional brasileiro, pela qual a educação no País é orientada historicamente para a formação de mão de obra para o mercado de trabalho.

As iniciativas de planejamento de viés social, iniciadas na década de 1950, no governo de Juscelino Kubitschek de Oliveira, foram interrompidas pelo governo militar instaurado pelo golpe de Estado de 1964, cuja orientação retoma a estrita relação entre planejamento social e econômico, o que afeta diretamente a educação, cujas políticas tomam uma direção técnico-profissionalizante.

O padrão gerencial de gestão educacional, instituído mais particularmente a partir da Reforma do Estado de 1990 contribui para a internalização das diretrizes internacionais no planejamento educacional, de forma a incorporar valores, objetivos e métodos do setor produtivo no setor educacional.

Somente no início do século XXI, a criação do PAR estabelece uma possibilidade de regulação do planejamento educacional de modo a articular, de forma orgânica, o papel indutivo da União com a autonomia dos entes federativos estaduais e municipais.

A continuidade do PAR no período de três governos do Partido dos Trabalhadores (2007-2015), assim como o seu êxito relativo na execução dos objetivos de traçar um planejamento educacional no Brasil, revelam sua importância para o regime de colaboração entre os entes da federação. Ainda que a colaboração financeira do governo tenha sido pequena em face da demanda dos municípios, não se pode negar que representou um esforço para garantir a elaboração dos planos municipais de educação e a concretização de muitas das ações previstas no instrumento do PAR.

Acima de tudo, o PAR representou uma inovação na educação brasileira porque possibilitou a prática de planejamento integrado com base nas necessidades que cada sistema reconhecia como importante. Essa possibilidade inovadora, em prática por um largo período de tempo, poderia conferir a autonomia e a responsabilidade coletiva próprias de um país organizado de forma federativa.

Todavia, esse processo de construção autônoma foi interrompido por um projeto político e econômico de retração dos direitos sociais em prol dos interesses que dominam a atual agenda global. Com isso, tanto o Plano Nacional de Educação (PNE) quanto a ação coletiva de planejamento dos sistemas educacionais se encontram ameaçados e sem força política para amadurecer. 


\section{REFERÊNCIAS}

BRASIL. Ministério da Educação. III Plano Setorial de Educação e Cultura: 1980-1985. Brasília: MEC, 1980.

. Ministério da Educação. Plano Setorial de Educação e Cultura: 1986-1989. Brasília: MEC, 1986.

. Ministério da Administração e Reforma do Estado. Plano Diretor da Reforma do Estado. Brasília: MARE, 1995.

. Ministério do Planejamento, Orçamento e Gestão, Secretaria de Planejamento e Investimento Estratégico. Plano Plurianual 2004-2007. Brasília: projeto de lei. Ministério do Planejamento, Orçamento e Gestão, Secretaria de Planejamento e Investimentos Estratégicos. Brasília: MP, 2003. Disponível em: www.planejamento.gov.br. Acesso em: 5 jul. 2016.

. Ministério do Planejamento, Orçamento e Gestão (2003). Plano Plurianual 2004 -2007. Brasília: MPOG, 2002.

. Ministério do Planejamento, Orçamento e Gestão. Plano Plurianual 2008-2010. Brasília: MPOG, 2007a.

. Decreto $n^{\circ}$ 6.094, de 24 de abril de 2007. Brasília: Câmara Legislativa, 2007b.

DUARTE, A.; FERREIRA, E. B. Política e gestão educacional: uma análise dos dados da pesquisa "trabalho docente na educação básica no Brasil". In: OLIVEIRA, D. A.; VIEIRA, L. F. (Org.). Trabalho na educação básica: a condição docente em sete estados brasileiros. 1ed.Belo Horizonte: Fino Traço Editora Ltda, 2012.

FAORO, R. Os donos do poder. São Paulo: Publifolha, 2014.

FERREIRA, E. B. O planejamento da gestão da educação profissional sob uma nova lógica de regulação social. In: Revista de Ciência e Tecnologia, v. 3, p. 26-36. Vitória: IFES, 2007.

. Democracia e tecnocracia no planejamento educacional brasileiro: tensões permanentes na educação do Século XXI. In: FERREIRA, E. B.; FONSECA, M. Política e planejamento educacional no Brasil do século XXI. Brasília: Liber Livro, 2013.

. Federalismo e planejamento educacional no exercício do PAR. Cadernos de Pesquisa. São Paulo: FCC, v. 44, n. 153, 2014.

FIORI, J. L. O voo da coruja: uma leitura não liberal da crise do Estado desenvolvimentista. Rio de Janeiro: Eduerj, 1995.

FONSECA, M. Planejamento educacional no Brasil: um campo de disputas entre as políticas de governo e as demandas da sociedade. In: FERREIRA, E. B.; FONSECA, M. Política e planejamento educacional no Brasil do século XXI. Brasília: Liber Livro, 2013.

. Políticas públicas para a qualidade da educação brasileira: entre o pragmatismo econômico e a responsabilidade social. Cadernos Cedes, v. 29, n. 78, Campinas: CEDES, 2009. 
FONSECA, M.; FERREIRA, E. B. Planejamento das políticas educativas no Brasil: tensões e desafios atuais. In: Revista Perspectiva. V. 29, p. 69-96 Florianópolis, 2011.

FONSECA, M.; TOSCHI, M. S.; OLIVEIRA, J. F. Educação, gestão e organização escolar: concepções e tendências atuais. In: Escolas gerenciadas: planos de desenvolvimento e projetos político-pedagógicos em debate. Goiânia: Ed. da UCG, 2004.

IANNI, O. Estado e planejamento econômico no Brasil. 5. ed. Rio de Janeiro: Civilização Brasileira, 1995.

LAFER, C. Observações sobre o plano de metas (1956-1961). In: MINDLIN, B. Planejamento no Brasil. São Paulo: Perspectiva, 2001.

LAVALLE, J. L. Instituciones e instrumentos para el planeamiento gubernamental em América Latina. In: CARDOSO JUNIOR, J. C. (Org.). A reinvenção do planejamento governamental no Brasil. Brasília: Ipea, 2011.

LOJKINE, J. A revolução informacional. São Paulo: Cortez, 1995.

MARTINS, P. S. O financiamento da educação básica por meio de fundos contábeis: estratégia política para a equidade, a autonomia e o regime de colaboração entre os entes federados. Tese (Doutorado) - Programa de Pós-Graduação em Educação da Universidade de Brasília. Brasília, 2009.

NEWMAN, J.; CLARKE, J. Gerencialismo. Educação \& Realidade. Porto Alegre, v. 37, n. 2, 2012.

RIFKIN, J. O fim dos empregos: o declínio inevitável dos níveis de emprego e a redução da força global de trabalho. [Trad. Ruth Gabriela Bahr]. São Paulo: Makron, 1995.

SCAFF, E. A. S. O modelo gerencial de gestão pública e sua aplicação na educação brasileira. In: LIMA, P. G.; FURTADO, A. C. (Org.). Educação brasileira: interfaces e solicitações recorrentes. Dourados, MS: UFGD, 2011.

SCAFF, E. A. S. FONSECA, M. Contribuições e limites do Plano de Ações Articuladas (PAR) para a efetivação da colaboração federativa. In: OLIVEIRA, J. F. de; AGUIAR, M. A. S. Planos de Educação e Ações Articuladas. Recife: PE, CCS Gráfica e Editora, 2016.

TORRE, S. de la. Innovacion educativa. Madri: Dykinson, 1997.

WEBER, M. Economia e Sociedade. Brasília: UNB, 1994.

Texto recebido em 05/05/2019.

Texto aprovado em 30/10/2019. 